\title{
Some Morphological Studies on the Jaw Joint of the Australian Saltwater Crocodile (Croco- dylus porosus)
}

\author{
A. S. Saber ${ }^{1}$ and A. Hassanin ${ }^{2}$ \\ ${ }^{1}$ Department of Anatomy and Embryology, Faculty of Veterinary Medicine, Uni- \\ versity of Sadat City, \\ Sadat City, Egypt \& Dicipline of Veterinary Sciences, College of Public Health, \\ Medical and Veterinary \\ Sciences, James Cook University, Townsville, Australia \\ ${ }^{2}$ Department of Cytology and Histology, Faculty of Veterinary Medicine, Univer- \\ sity of Sadat City, Sadat City, Egypt.
}

$\overline{\text { With } 10 \text { figures, } 4 \text { tables } \quad \text { Received May, accepted for publication June } 2014}$

\section{Abstract}

The saltwater crocodile is the largest of all living reptiles. It is also known and proved that it has the largest biting forces. The magnitude of the biting force exerted by the jaw leads to thoughts about the anatomical structure and construction of the jaw joint in this reptile. Thirteen skulls of the saltwater crocodile (C. porosus) were used for this study. Some skulls were used for X-raying and morphology, and the others for histological slides which were prepared from the articular cartilages, capsule and collateral ligaments. The quadrate/articular joint (jaw joint) was diarthroidal, formed by two articular surfaces, which were fibrocartilage in nature at the periphery of the articular surface, hyaline in the rest of the articular surface, and ossifies on reaching the underlying bone.

The thick lateral and thin medial collateral ligaments were formed of collagenous fibers. An articular disc was missing in the crocodile quadrate/articular joint. The joint was surrounded by a complex massive group of muscles responsible for the firm closure and opening of the mouth.

The results were supported by 10 images and 4 tables, and were discussed with other amphibians, domestic animals and man when needed. 
Keywords: Jaw joint, quadrate-articular joints, morphology, saltwater crocodile

\section{Introduction}

The saltwater crocodile, also known as the Estuarine or IndoPacific crocodile, is the largest of all living reptiles. It is known and it has been proven that it has the strongest biting forces. Comparison of Alligator mississippiensis biting forces with some of the large known values in the literature for other gnathostomes (measured using bite bars and theoretical measures employing various modeling techniques) (Snodgrass and Gilbert, 1967; Dechow and Carlson, 1983; Thomson and Holm, 1992; Binder and Van Valkenburgh, 2000) suggests that crocodile bite forces are the highest known for any living taxon (Tables 1, 2). Singha (2013) also mentioned that certain bite tests in laboratory settings conducted by experts have confirmed the saltwater crocodile as the ultimate chomper of the wild; the reptile can shut its jaw with an unbelievable force of 3.700 pounds per square inch (PSI). Erickson (2012) also measured the saltwater crocodile's bite power at 3,700 psi $\quad(16.460$ newtons). He added that by con- trast, Hyenas, lions and tigers generate around 100 psi (4.450 newton).

Animals, which must exert powerful bite forces, such as crocodiles, often have rigid skulls with little or no kinesis for maximum strength (lordansky, 1964). This author added that most reptile skulls are dikinetic, having both meta- and meso-kinetic joints. The mandibulo-quadrate joint also articulates with the (palatine-pterygoid) bar, which, then connects to the maxilla, so that when the quadrate is pulled towards the skull by the muscles the bar pushes on the base of the maxilla and causes the upper jaw to open.

This magnitude of the biting force exerted by the jaw is the reason for our investigation of the anatomical structure and construction of this jaw in this reptile.

The temporomandibular joint (TMJ), also known as jaw joint or mandibular joint in mammals, is an ellipsoid variety of synovial joint, paired right and left to form a bicondylar articulation (Williams et al, 1999).

Herring (2003) mentioned three interesting facts about the TMJ. 
Its constituent bones, the mandible and the squamous temporal, are intramembranous in origin. Thus, the tissue that covers each articulating surfaces is a secondary cartilage with a fibrous coat, derived from the periosteum. Another feature is the disc, which even when incomplete, is associated with the lateral pterygoid muscle (Sprinz, 1965). This arrangement has led some authors to speculate that it arose as a tendon, which became pinched, by the new joint (Du Brul, 1964). The third feature of the TMJ is its role in growth: i.e. the secondary condylar cartilage is a major growth site in addition to being an articular covering.

Among the great number of papers published on crocodiles and alligators and their relatives, only two very old manuscripts were found which dealt with the anatomy of the crocodile's quadrate/articular joint (Parsons, $1900)$ and the cranial musculature (Edgeworth, 1935). Hence, the aim of this study is to explore the nature and give more morphometric measurements and morphological description of this joint in the saltwater crocodile.

\section{Material and Methods}

Ten saltwater crocodile heads (Crocodylus porosus) donated by a crocodile farm in Cairns, Queensland, Australia, as well as four skulls bought at the Kotter Market, Townsville, and one skull kept in the anatomy museum in the School of Veterinary and Biomedical Sciences, JCU, Townville, were used in this study.

One crocodile head was used for $x$-raying; two heads were cut sagittaly for $\mathrm{x}$-raying and jaw muscle study. The other 7 heads were dissected from both sides to study the jaw joint (its ligaments, joint capsule, articular surfaces) as well as the muscles surrounding the joint and acting on it. Small pieces from the articular surface, joint capsule and collateral ligaments were processed with routine histological methods, cut with the microtome (5 $\mu \mathrm{m}$ thick) and stained with H\&E, Periodic acid Schiff (PAS) and Masson's trichrome stains, and finally photographed with an Olympus microscope equipped with a camera (Imaging, Micro Publisher 5.0 RTV).

The skulls were prepared using the boiling maceration technique for skeleton preparation described by Simoens et al., (1994) and the measurements 
were taken using a normal caliper. Gross photographs were taken by a Samsung digital camera WB 700. Nomina Anatomica Veterinaria (2005) was utilized for denominating the anatomical terms in the study.

\section{Results}

The jaw or quadrate/articular joint of the saltwater crocodile (C. porosus) was a synovial, ellipsoidal, condylar joint. The measurements taken for the crocodile skulls which house the joint (skull length, skull weight with the mandible and without it) are given in table (3). The measurements of the articular surfaces of the joint are given in table (4). The quadrate/articular joint was formed of the following components:

\section{Articular surfaces}

\section{(i) Mandibular component}

The mandible of the crocodile was formed of six fused bones (dentary, angular, sur-angular, splenial, coronoid, and articular) (Fig. 1). The articular was the bone which presents the concave articular surface (1.5-2.8 $\mathrm{cm}$ long) configured as two surfaces: the larger lateral one measuring about $1.5 \mathrm{~cm}$ long and smaller medial surface about $1 \mathrm{~cm}$ long. Both surfaces were firmly adhering to the condyle of the quadrate bone (Figs $2,8)$.

In two cases (smaller skulls) out of ten, the articular cartilage was found loosely attached to the articular bone of the mandible in the first case, and in the other case only the lateral part was loose and its medial facet was attaching the bone (Fig 2/B).

An articular disc like found in the majority of the mammalian and reptilian jaw joints could not be observed in the jaw joint of the crocodiles of this study.

\section{(ii) Cranial component}

The articular surface of the quadrate bone was formed of a transversely oriented oval surface (1.7-2.5 cm in length), which was constricted in its middle leaving a larger lateral condyle and medial smaller one (Fig. 3).

\section{(iii) Histological structure of the articular surface}

Microscopic examination of the articular surface of the condyles illustrated that it is formed of an outer fibrous tangential layer; middle hyaline cartilage layer and deep calcified layer terminate in the bone of the mandible 
(Figs 4/A \& 6/B). The tangential layer is the superficial layer of the articular surface, similar to the perichondrium of other cartilages; it is formed of small, flattened chondrocytes and collagen fibers that run parallel to the articular surface (Fig 4). The collagen fibers stained deep blue while the cartilage matrix was light blue with Masson's trichrome (Fig 6/A). The hyaline cartilage formed from chondrocytes inside lacunae either singly or in groups (isogenous) embedded in the matrix (Figs 4, $5,6)$. The deep calcified layer rests on the underlying cortex of the bone. It is transit zone between the articular cartilage and the bone structure of the mandible. The chondrocytes are arranged in rows perpendicular to the articular surface, it show pyknotic dark nuclei (Figs 4/A \& $5 / A)$. The matrix of the calcified cartilage layer stains slightly darker (PAS) than the matrix of the other layers (Fig 6/A).

\section{Articular capsule (fibrous \& synovial)}

The articular capsule was a tight sleeve investing the mandibular joint completely. It is attached at the margins of the articular surface of both the quadrate and articular bones. The capsule is capacious enough to permit easy movement of the joint (Fig 7).

\section{Articular ligaments}

Two collateral ligaments were found to tightly bind the joint surfaces together. The lateral collateral ligament is thick, $20 \mathrm{~mm}$ long and $7 \mathrm{~mm}$ wide, covering nearly the whole lateral side surface of the joint. Microscopically, it was formed of dense regular connective tissue formed of collagen bundles and fibrocytes run parallel with axis of the collagen fibers as shown in (Fig 5/B). The medial collateral ligament was thinner and shorter than the lateral one, measuring $13 \mathrm{~mm}$ long and $3 \mathrm{~mm}$ wide. It was attached at the middle of the medial surface of the joint (Fig 7).

\section{Surrounding muscles}

The quadrate/articular joint was supported by a powerful muscular mass encircling it and helping its action of opening and closing firmly the mouth. The muscles mostly arose from the lateral wall of the braincase, to end in the mandible (Figs 9,10). These muscles namely are:
a) M. adductor mandibularis externus superficialis, 
b) M. adductor mandibularis externus media,

c) M. adductor mandibularis externus profundus,

d) M. adductor mandibularis caudalis (posterior).

e) M. pseudotemporalis superficialis,

f) M.pseudotemporalis profundus,

g) M. pterygoideus dorsalis,

h) M. pterygoideus ventralis,

i) $M$. intramandibularis,

j) M. depressor mandibulae.

\section{Discussion}

(N.B. due to the paucity of research found on the jaw joint anatomy in crocodiles, comparison was made to some domestic animals and man when needed)

The temporomandibular joint (TMJ) is a cardinal feature that defines the class Mammalia and separates mammals from other vertebrates (Herring, 2003). The crocodile skull, including the mandible, is pneumatized in nature with plenty of foramina on the dorsal aspect and lateral sides of the skull and the lateral sides of both rami of the mandible. The mandible is formed of six completely fused bones, from which the articular bone shares in the formation of the jaw joint. lordansky (1964) mentioned that animals, which must exert powerful bite forces such as crocodiles, often have rigid skulls with little or no kinesis for maximum strength

Douglas (1999) comparing between reptiles and mammals mentioned that reptiles have at least four bones in the lower jaw (e.g. the dentary, articular, angular, surangular, and coronoid), while mammals have only one (the dentary). In the crocodile of this study, six fused bones forming the mandible were identified.

In man, the adult mandibular condyle varies considerably in form from that found in the young child. In the former, the neck is thin and elongated and is readily fractured (Patnaik, 2000). In the infant the condyle is short and stubby having a copious blood supply (Blackwood, 1965).

Absence of the articular disc in the crocodilian jaw joint of this study may be interpreted to the very close and firm adaptation of both articular surfaces forming the joint to each other, preventing any possibility to a lateral movement. 
Parsons (1900) stated that the meniscus is a very constant structure in Mammalia but may be "suppressed or underdeveloped" in a very small number of animals. He found no evidence of a disc in the mandibular joints of Dasypus (armadillo), Dasyurus ursinus (Tasmanian devil), Ornithorhynchus (duck-bill platypus) and Tachyglossus (Echidna or spiny anteater).

Sprinz (1965) confirmed the absence of the disc in Dasyurus (native Australian rat) and the presence of remnants of discs represented by fine fibrous strands in Tachyglossus (Echidna), Ornithorhynchus (Platypus) and Sarcophilus (Tasmanian devil). He added that complete discs, which are attached to the joint surfaces, are present in Didelphus (Virginian opossum) and Metachirus (rat-tailed opossum). The disc ensures frictionreduced sliding, damping and diversion of peak load (Mc Donald (1989). A reduction in disc thickness increases strain (Nickel and Mc Lachlan, 1994).

Herring et al., (2002) mentioned that the pig TMJ is better supported than that of humans laterally and medially, but more vulnerable caudally. The caudal attachment area of the intra- articular disc is fibro-fatty rather than vascular, as human.

The articular cartilages of the crocodile jaw joint were of both fibrocartilaginous nature at the articular surface and merged into the hyaline nature then calcified transit zone at the attachment of the underling bone. Samuelson (2007) mentioned that fibrocartilage is found at intervertebral discs and certain ligamentous and tendinous attachments to bones and menisci of stifle joints. He added that the fibers bundles often assume a herringbone pattern as individual bundles crisscross each other in an interwoven $\mathrm{V}$ shape. Fibrocartilage is often associated with both dense connective tissue and hyaline cartilage, typically merging imperceptibly with them. The same author confirmed that the matrix of the fibrocartilage is basically similar to that of the hyaline cartilage, and the chondrocytes are aligned in rows, much like fibrocytes within tendons and ligaments. Kerr (2009) mentioned that the band of striations (Fig 5/A of this work) that correspond to aggregates of mineral (calcium) depositing by matrix vesicles produced by nearby chondrocytes is called tidemark. He added that calcium and hydrox- 
yapatite crystals accumulate in the matrix vesicles, and their contents of specific glycoprotein, abundant in the tidemark zone, induce calcium phosphate (hydroxyapatite) deposition in association with binding to matrix collagen.

Patil and Bindra (2012) stated that the ligaments on the lateral side of the sheep TMJ attach to the zygomatic arches and retroarticular processes, and ventrally to the mandibular neck. These ligaments are incorporated into the joint capsules and stabilize the intra-articular discs (Maynard and Savage, 1959 \& Jochen and Tomasz, 2007)

In monotremes, the pterygoid muscles have fused into a single unit (Edgeworth, 1935). According to Abbie (1939) in macropodians the complex masseter, pterygoid and temporalis musculature are closely set together, and separation into distinct muscles is not possible by dissection (as the case in the crocodile of the present study). Ride (1959), whilst agreeing with Abbie (1939), stated however that the muscle acted as if they were isolated units. Sprinz (1965) added that in all joint studies a muscle (lateral pterygoid) was attached to the medial pole of the condyle. The Muscle pterygoideus caudalis was relatively smaller in three species compared with many short-snouted crocodiles. It suggests that the masticatory power in a fisheating long-snouted species is not as high as in the shortsnouted crocodiles. The false gavial and the African slendersnouted crocodiles had the pterygoid bone well developed extending dorso-ventrally and it is suggested that the $M$. adductor mandibulae caudalis attached to the pterygoid bone may be much larger than the Indian gavial. (Endo et al., 2002).

The $\mathrm{Mm}$. adductor mandibulae externus, adductor mandibulae posterior (caudalis), and pterygoideus activate bilaterally and simultaneously during rapid closing or crushing. The M. pterygoideus does not act during prey holding whereas the $\mathrm{Mm}$. adductor mandibulae externus, adductor mandibulae caudalis continue to be active. The $\mathrm{Mm}$. depressor mandibulae and intramandibularis are variably active during both jaw opening and closing (Busbey, 1989).

The complex grouping of the jaw muscles found in this study resembles that described for the American alligator (Alligator 
mississippiensis) by Holliday et al. (2013)

Patnaik (2000) mentioned that the smooth slippery, pressurebearing tissue carpeting the bearing areas of the jaw joint of humans varies in thickness across different articular areas. It is essentially a bed of tough collagen fibers bound by special glycoproteins. He also described the histological structure of the articular surface as consisting of 4 successive layers; (1) horizontal, thick tightly packed, collagen fibers, (2) oblique fibers leading into (3) strong vertical fibers with scattered cartilage cells emerging from (4) calcified cartilage overlying thin layer of cortical bone. In the crocodile of this study only three layers were distinguished; tangential layer, hyaline cartilage and calcified cartilage layers.

Patnaik (2000) described two layers forming the lateral collateral ligament of the human TMJ; a wide outer or superficial layer (fan-shaped) and a narrow inner or deep band. He added that there is no comparable doublelayered reinforcement on the medial side of condyle, but a medial horizontal band is present at a lower level. Nell et al., (1996) had described various macroscopic and microscopic variations in the human TMJ ligaments. In the crocodiles of the present study, the lateral collateral ligament was formed only of one thick layer, while the medial collateral ligament was thinner and shorter.

\section{Conclusion}

- The quadrate/articular joint of the saltwater crocodile is diarthroidal, and its articular surfaces match very well to each other, preventing any side movement.

- The articular cartilage is of the fibrocartilage type at the periphery of the articular surface, hyaline in nature at the rest of the surface, and ossifies on reaching the underlying bone.

- The joint capsule is tight and the collateral ligaments are two; lateral and medial shorter and thinner.

- There is no articular disc in the crocodile jaw joint.

- The peculiar anatomical feature of the crocodile jaw joint together with the interdigitating arrangement of the mandibular and maxillary 
teeth is responsible for the tremendous biting force performing by crocodiles.

\section{Acknowledgement}

We want to express our appreciation and thanks to Mrs. Elaine Wright and Mr. Bruce Clark, Farm managers in Cairns Crocodile Farm, QLD, Australia for donating the crocodile heads of this study. Our thanks are also extended to Mrs. Kerry Johns for preparing the crocodile skulls and to Mr. Laurie Reilly, the senior histology technicians officer, School of Veterinary and Biomedical Sciences, JCU, Townsville, for preparing the histological slides, and to Dr. Fernando Liste Burillo for the $\mathrm{x}$-ray imaging.

\section{References}

Abbie, A.A. (1939): A masticatory adaptation peculiar to some diprotodond marsupials. Proc. zool. Soc. Lond., B 109: 261279

Blackwood, H.J.J. (1965): Vascularization of the condylar cartilage in the human mandible. Journal of Anatomy, 99: 551-63.

Binder, W. J. \& Van Valkenburgh, B. (2000): Development of bite strength and feeding be-

J. Vet. Anat. havior in juvenile spotted hyenas (Crocuta crocuta). J. Zool. (Lond.) 252: 273-283.

Busbey, B. (1989): Form and function of the feeding apparatus of Alligator mississippiensis. Journal of Morphology, Volume 202, Issue 1, pages 99 127, October

Dechow, P. C. \& Carlson, D. S. (1983): A method of bite force measurement in primates. $J$. Biomech. 16: 797-802.

Douglas, T (1999): Evidences for Macroevolution, Part 1: The Unique Universal PhylogenicTree.

http://www.talkorigins.org/faqs/c omdesc/section1.html (retrieved 28/10/2013)

Du Brul E.L. (1964): Evolution of the temporomandibular joint. in: Sarnat BG, editor. The temporo-mandibular joint. Charles $\mathrm{C}$ Thomas; Springfield, IL: 3-27

Edgeworth, F.H. (1935): The cranial muscles of vertebrates. Cambridge: University Press.

Endo, H., R. Aoki, H. Taru, J. Kimura, M. Sasaki, M. Yamamoto, K. Arishima, and Y. Hayashi (2002): Comparative functional morphology of the masticatory apparatus in the 
long-snouted crocodiles. Anatomia, Histologia, Embryologia 31(4): 206-213.

Erickson, G.M. (2012): Crocodiles have strongest bite ever measured, hands-on tests show. http://www.news.nationalgeogra phic.com/news/2012/03/120315. (Retrieved 22.10.2012)

Erickson, G.M.; Lappin, A.K. and Vliet, K.A. (2003): The ontogeny of bite-force performance in American Alligator (Alligator mississippiensis). J. Zool. Lond, 260: 317-327

Herring S.W. (2003): TMJ anatomy and animal models. J Musculoskelet Neuronal Interact, 3 (4): 391

Herring S.W., Decker J.D., Liu Z.J. and Ma T. (2002): Temporomandibular joint in miniature pigs: anatomy, cell replication, and relation to loading. Anat Rec., 266: 152-166

\section{Holliday CM, Tsai HP, Skiljan} RJ, George ID, Pathan S (2013): A 3D Interactive Model and Atlas of the Jaw Musculature of Alligator mississippiensis. PLoS ONE 8(6): e62806. doi:10.1371/journal.pone.00628 06 http://www.plosone.org/article/inf o\%3Adoi\%2F10.1371\%2Fjourna I.pone.0062806

(retrieved 26/10/2013)

lordansky, N.N. (1964): The jaw muscles of the crocodiles and some relating structures of the crocodile skull. Anat Anz., Oct 13, 115: 256-280

Jochen, F. and Tomasz, G. (2007): "On the Development, Morphology and Function of the Temporomandibular Joint in the Light of the Orofacial System". Annals of Anatomy- Anatomischer Anzeiger, Vol.189, No. 4: 314-319

Kerr, J.B. (2009): Functional Histology. $2^{\text {nd }}$ ed., Mosby, Elsevier.

Maynard, S.J. and Savage, R.J.G. (1959): "The Mechanics of Mammalian Jaws", School Science Review, Vol. 40, No. 4: 289-301.

Mc Donalnd, F. (1989): The condylar disc as controlling factor in form of condylar head. J.Craniomandibular. Dosoral. 3: 83-86

Nell, A; Niebauer, W; Sperr, W. and Firbas, W. (1996): Special variation of lateral ligament of 
human TMJ. Clinical Anatomy, 7: 267-70.

Nickel, J.L. and Mc Lachlan, K.R. (1994): In vitro of the temporomandibular joint disc. Arch.Oral Biol., 39: 323-331.

Parsons F.G. (1900): The joints of mammals compared with those of man. J. Anat., London, 34: 41-68

Patil, A.S. and Bindra, G.K. (2012): Morphology of the temporomandibular joint (TMJ) of sheep (Ovis aries), Open Journal of Veterinary Medicine, Vol.

2 No. 4,242-244

Patnaik V.V.G. (2000): Anatomy of Temporomandibular Joint? A Review. J Anat. Soc. India 49(2) 191-197

Ride, W.D.L. (1959): Mastication and taxonomy in the macropodine skull. In Function and taxonomic importance. Publ. Syat. Ass., No 3: 33-59

Samuelson, D.A. (2007): Text Book of Veterinary Histology. Saunders, Elsevier

Simoens, R., Poles, R. and 'lauwers, H. (1994): Morphometric analysis of foramen magnum in Pekingese dogs. Ameri- can Journal of Veterinary Research, 55: 33-39.

Singha, R. (2013): Animals with the most powerful bite force http://www.buzzle.com/articles/a nimals-with-the-most-powerfulbite-bite-force.html

Retrieved 17.10.2013

Snodgrass, J. M. \& Gilbert, P. W. (1967): A shark bite meter. In Sharks, skates, and rays: 331337. Gilbert, P. W., Mathewson,R. F. \& Rall, D. P. (Eds). Baltimore: Johns Hopkins University Press.

Sprinz R.A. (1965): A note on the mandibular intra-articular disc in the joints of marsupialia and Monotremata. Proc Zool Soc London; Vol. 144, Issue 3: 327-337

Thomson, D. \& Holm, S. (1992): Bite force development, metabolic and circulatory response to electrical stimulation in the canine and porcine masseter muscles. Arch. Oral Biol. 37: 997-1006.

Williams P.L.; Bannister, L.H.; Berry, M.M; Collins, P. Dyson, M; Dussek, J.E; Ferguson, M.W.J.(1999): Gray's Anatomy In: Skeletal System 38th Edn, 
Churchill Livingstone, London: pp 578-82

Internet links:

1) http://forums.sherdog.c om/forums/f48/top-20worlds-strongestanimal-bite-forces-new2393047/ (Retrieved $11 / 2 / 2014)$
2) http://listverse.com/201 2/11/05/top-10-animalbites-that-willcompletely-destroyyoul

(Retrieved 11/2/2014)

3) http://www.pawnation.c om/2012/12/18/12-mostpowerful-bites-in-theanimal-kingdom/12

(Retrieved 11/2/2014)

Table (1): Comparison of Alligator mississippiensis biting forces with some the largest values in the literature for other gnathostomes estimated in Newton (N). Source: (Erikson et al., 2003)

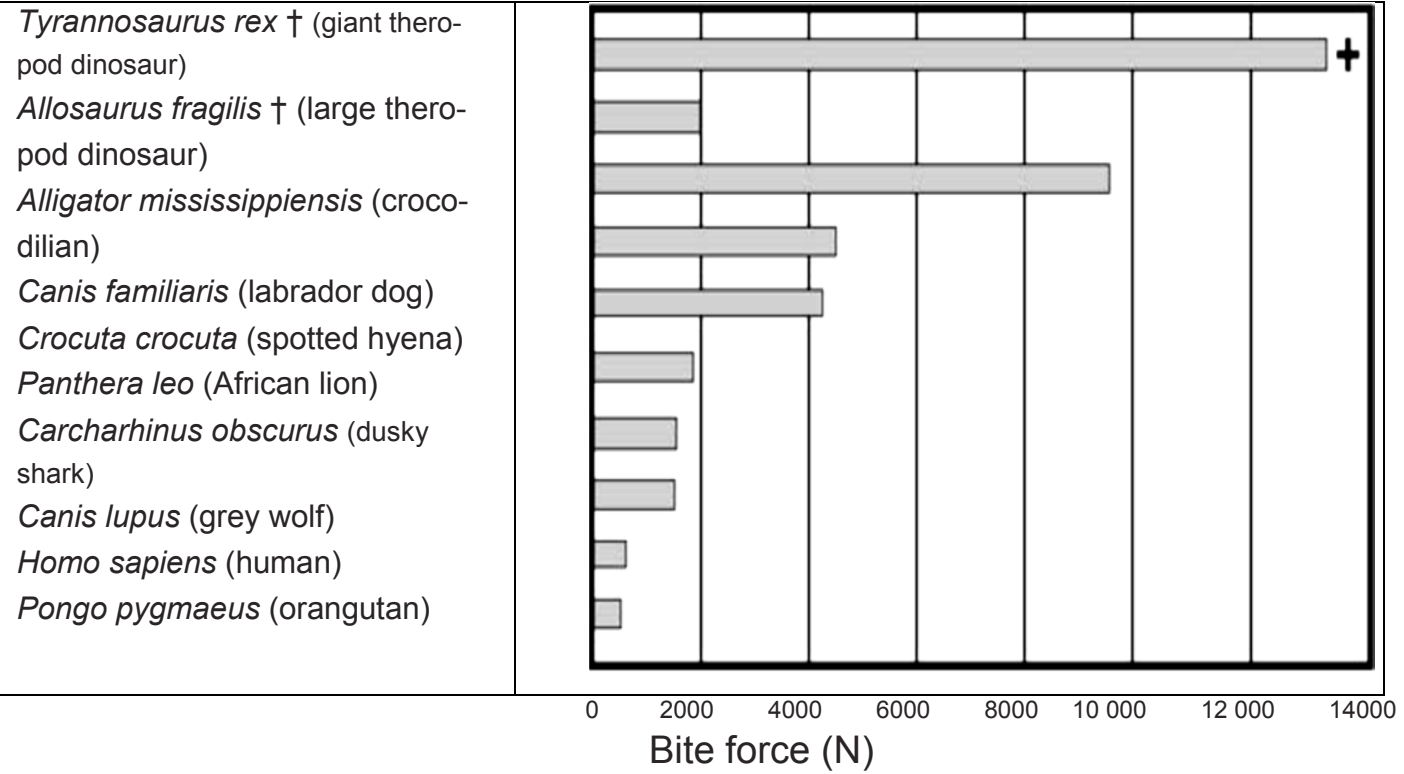


Table (2): Comparison of saltwater crocodile biting forces with some the largest values estimated for other mammals expressed in pound per square inch (psi). (Source: compiled from Singha, $3013 \& 1,2,3)$

\begin{tabular}{|l|c|}
\hline \multicolumn{1}{|c|}{ Animal } & Bite force (psi) \\
\hline Human & 150 \\
\hline Tasmanian devil & 181 \\
\hline Grey Wolf & 406 \\
\hline Mastiff Dog & 235 \\
\hline Great white Shark & 669 \\
\hline Lion & $650-691$ \\
\hline Alligator Sn apping turtle & 1.000 \\
\hline Grizzly bear & 1.050 \\
\hline Hyena & 1.100 \\
\hline Gorilla & 1.300 \\
\hline Jaguar & 1.350 \\
\hline Hippopotamus & 1.825 \\
\hline Alligator & 2.125 \\
\hline Saltwater crocodile & 3.700 \\
\hline
\end{tabular}

Table (3): Measurements of the skulls used in this study

\begin{tabular}{|c|c|c|c|}
\hline Skulls & Mandible weight/gm & Maxilla weight/gm & Skull Length/cm \\
\hline Skull 1 & 103.85 & 171.82 & 27.00 \\
\hline Skull 2 & 168.74 & 259.29 & 30.00 \\
\hline Skull 3 & 169.08 & 264.80 & 30.00 \\
\hline Skull 4 & 536.70 & 799.97 & 40.00 \\
\hline Skull 5 & 130.00 & 348.00 & 26.3 \\
\hline Skull 6 & 146.00 & 288.00 & 27.00 \\
\hline Skull 7 & 106.00 & 175.00 & 24.6 \\
\hline Skull 8 & 97.00 & 153.00 & 24.5 \\
\hline Skull 9 & $\mathbf{1 0 4 . 0 0}$ & 167.00 & 25.00 \\
\hline Skull 10 & $\mathbf{8 3 . 0 0}$ & 185.00 & 24.00 \\
\hline Skull 11 & $\mathbf{1 0 4 . 0 0}$ & 165.00 & 24.00 \\
\hline Skull 12 & $\mathbf{1 0 9 . 0 0}$ & 172.00 & 26.00 \\
\hline Skull 13 & $\mathbf{9 8 . 0 0}$ & 158.00 & 25.00 \\
\hline MEAN & $\mathbf{1 1 8 . 2 2}$ & $\mathbf{2 0 8 . 9 0}$ & $\mathbf{2 6 . 1 2}$ \\
\hline SD & $\mathbf{1 7 . 8 9}$ & $\mathbf{6 4 . 6 3}$ & $\mathbf{1 . 0 3}$ \\
\hline Max & $\mathbf{1 6 8 . 7 4}$ & $\mathbf{3 4 8}$ & $\mathbf{3 0}$ \\
\hline Min & $\mathbf{8 3}$ & $\mathbf{1 5 3}$ & $\mathbf{2 4}$ \\
\hline
\end{tabular}

N.B. Crocodile No 4 was excluded from the calculations as it is the only very bigsized one 
Table (4): Measurements of the articular surfaces taken on both the skull (quadrate bone) and the mandible (articular bone)

\begin{tabular}{|c|c|c|c|c|c|c|c|c|}
\hline \multirow{2}{*}{$\begin{array}{l}\text { Skulls } \\
\text { Skulls }\end{array}$} & \multicolumn{4}{|c|}{$\begin{array}{l}\text { Measurement on the } \\
\text { Skull (quadrate) }\end{array}$} & \multicolumn{4}{|c|}{$\begin{array}{c}\text { Measurement on the } \\
\text { Mandible (articular) }\end{array}$} \\
\hline & $\begin{array}{c}\text { Side/ } \\
\text { side } \\
\text { lengt } \\
h\end{array}$ & $\begin{array}{c}\text { Front/ } \\
\text { back } \\
\text { length } \\
\text { (M) }\end{array}$ & $\begin{array}{c}\text { Front/ } \\
\text { back } \\
\text { length } \\
\text { (Mi) }\end{array}$ & $\begin{array}{c}\text { Front/ } \\
\text { back } \\
\text { length } \\
\text { (L) }\end{array}$ & $\begin{array}{l}\text { Side/ } \\
\text { side } \\
\text { length }\end{array}$ & $\begin{array}{c}\text { Front/ } \\
\text { back } \\
\text { length } \\
\text { (M) }\end{array}$ & $\begin{array}{c}\text { Front/ } \\
\text { back } \\
\text { length } \\
\text { (Mi) }\end{array}$ & $\begin{array}{c}\text { Front/ } \\
\text { back } \\
\text { length } \\
\text { (L) }\end{array}$ \\
\hline Skull 1 & 1.9 & 1.1 & 0.6 & 0.9 & 2.1 & 1.5 & 1.3 & 0.8 \\
\hline Skull 2 & 2.2 & 1.0 & 0.5 & 2.3 & 1.5 & 2.5 & 1.0 & 1.5 \\
\hline Skull 3 & 2.5 & 1.0 & 0.7 & 1.0 & 2.8 & 1.2 & 1.4 & 1.9 \\
\hline Skull 4* & 3.5 & 1.5 & 0.9 & 1.5 & 4.0 & 2.4 & 1.7 & 1.9 \\
\hline Skull 5 & 2.3 & 0.9 & 0.7 & 0.8 & 2.3 & 1.0 & 1.2 & 1.7 \\
\hline Skull 6 & 2.4 & 0.9 & 0.6 & 0.9 & 2.7 & 1.8 & 1.4 & 1.7 \\
\hline Skull 7 & 1.9 & 0.7 & 0.5 & 0.7 & 1.8 & 1.4 & 1.1 & 1.5 \\
\hline Skull 8 & 2.0 & 0.6 & 0.3 & 0.8 & 2.0 & 0.7 & 1.1 & 1.3 \\
\hline Skull 9 & 1.8 & 0.7 & 0.5 & 0.6 & 1.7 & 0.9 & 1.0 & 1.2 \\
\hline Skull 10 & 1.7 & 0.7 & 0.4 & 0.6 & 1.6 & 1.0 & 0.9 & 1.4 \\
\hline Skull 11 & 2.0 & 1.1 & 0.6 & 0.8 & 1.7 & 1.5 & 1.1 & 1.4 \\
\hline Skull 12 & 2.1 & 1.6 & 1.1 & 1.6 & 1.9 & 1.0 & 0.6 & 0.9 \\
\hline Skull 13 & 1.7 & 1.1 & 0.6 & 1.0 & 1.6 & 1.2 & 1.2 & 1.3 \\
\hline MEAN & 1.98 & 0.98 & 0.59 & 0.87 & 1.9 & 1.17 & 1.07 & 1.38 \\
\hline SD & 0.23 & 0.92 & 0.21 & 0.29 & 1.35 & 0.32 & 0.2 & 0.23 \\
\hline Max & 2.4 & 1.6 & 1.1 & 1.6 & 2.7 & 1.8 & 1.1 & 1.7 \\
\hline Min & 0.23 & 0.29 & 0.21 & 0.29 & 0.35 & 0.32 & 0.21 & 0.23 \\
\hline
\end{tabular}

N.B. Crocodile No 4 was excluded from the calculations as it is the only very bigsized one. 


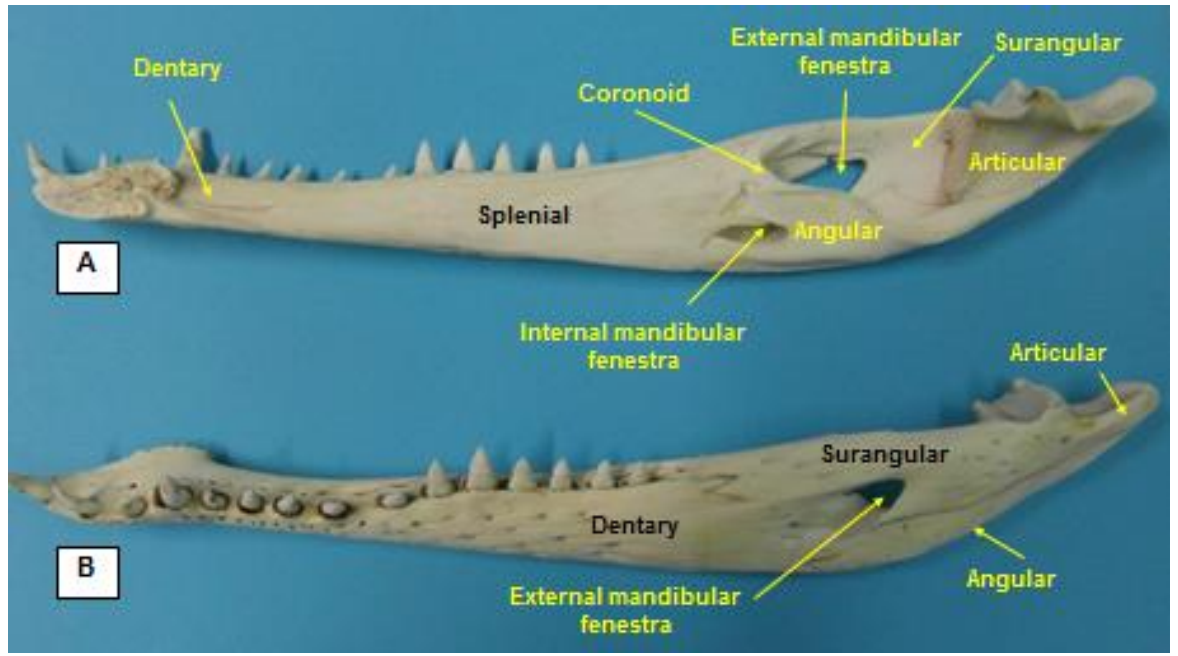

Fig (1): Medial surface of the mandible right ramus $(A)$ and lateral surface of the mandible left ramus $(B)$ showing its six fused bony components (dentary, articular, angular, surangular, coronoid and splenial).
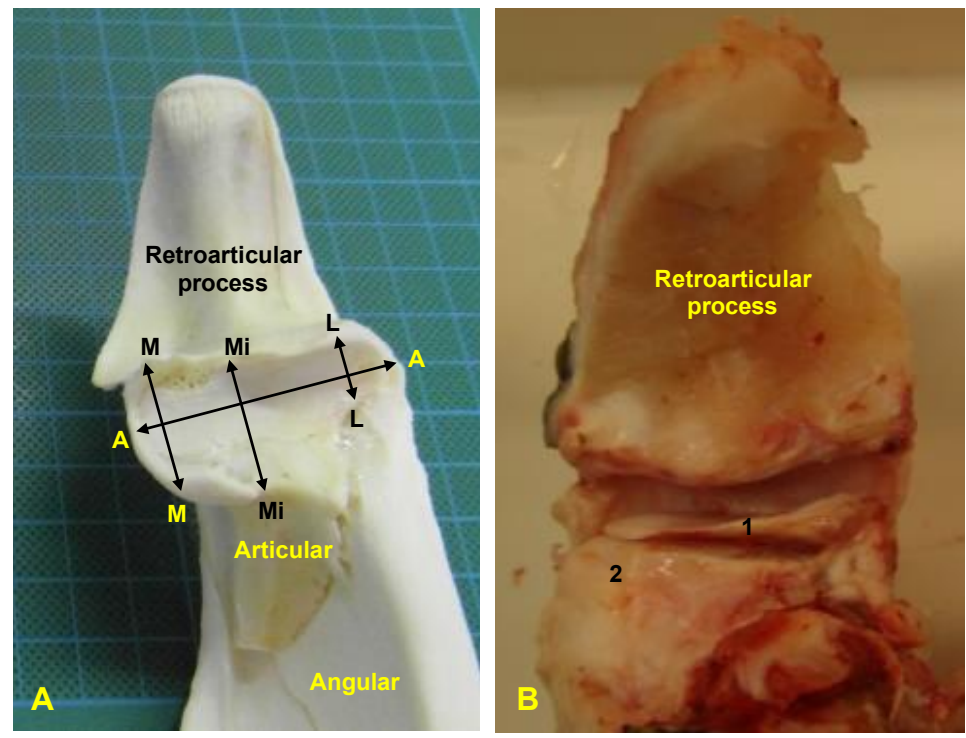

Fig (2, A): Articular surface of the left ramus of the mandible in Crocodylus porosus. A-A side to side length, M-M medial front to back length, Mi-Mi middle front to back length, $L-L$ lateral front to back length.

Fig (2, B): Rostral view of a fresh left articular part of the quadrate/articular joint showing: 1 un-fused articular cartilage covering the articular surface of the bone, 2 rostral border of the articular surface on the articular bone. 


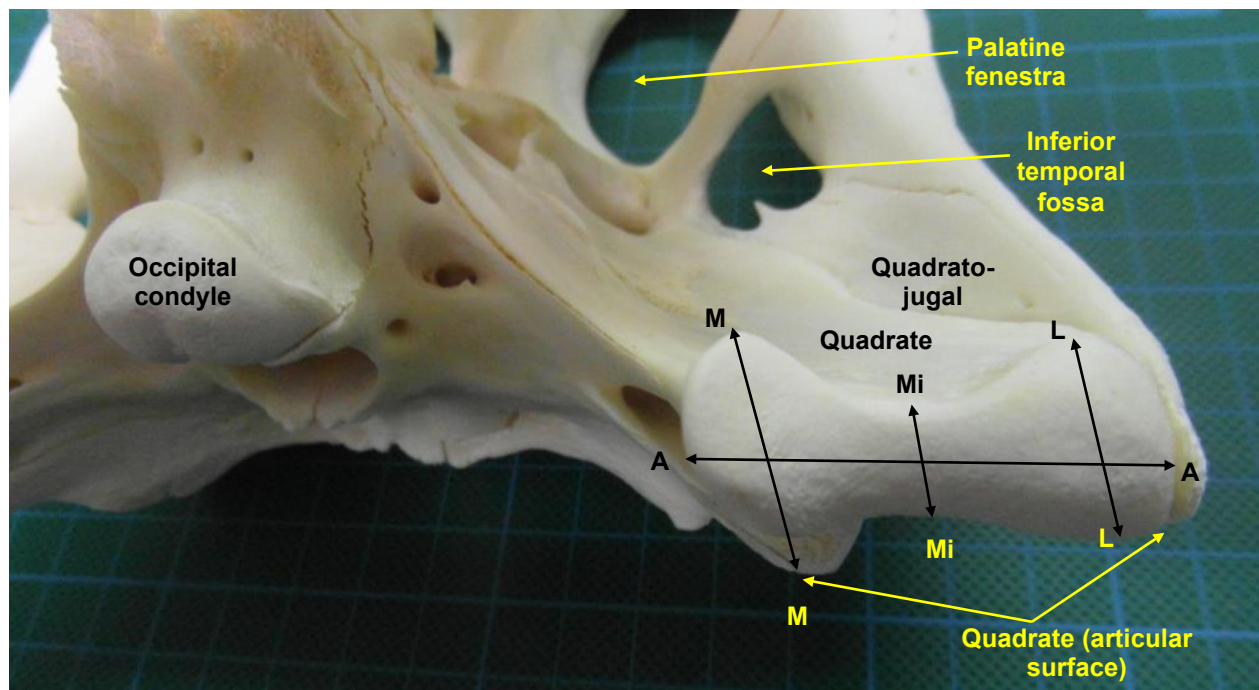

Fig (3): Left articular surface of the quadrate bone of Crocodylus porosus. A-A side to side length, M-M medial front to back length, Mi-Mi middle front to back length, L-L lateral front to back length.

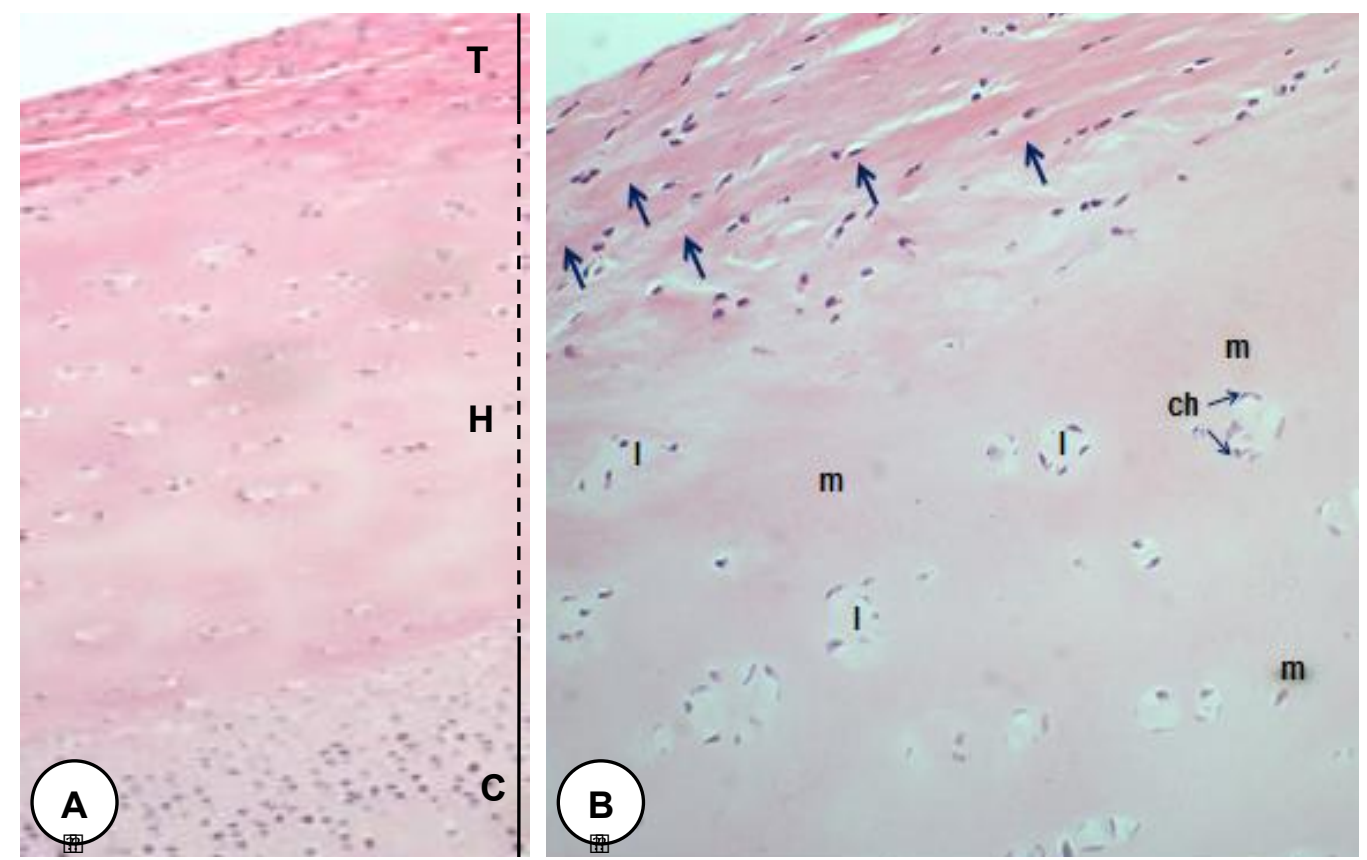

Fig (4): Light micrograph of the articular surface of the crocodile quadrate/articular joint showing: A. three distinct layers; $(\mathbf{T})$ tangential layer, $(\mathbf{H})$ hyaline cartilage and $(\mathbf{C})$ calcified cartilage layer (H\&E stain; x20). B. higher magnification showing the tangential fibrocartilaginous layer (arrows) and proper cartilage layer with chondrocytes (ch) singly or in isogenous (I) imbedded in matrix (m). (H\&E stain; x40) 


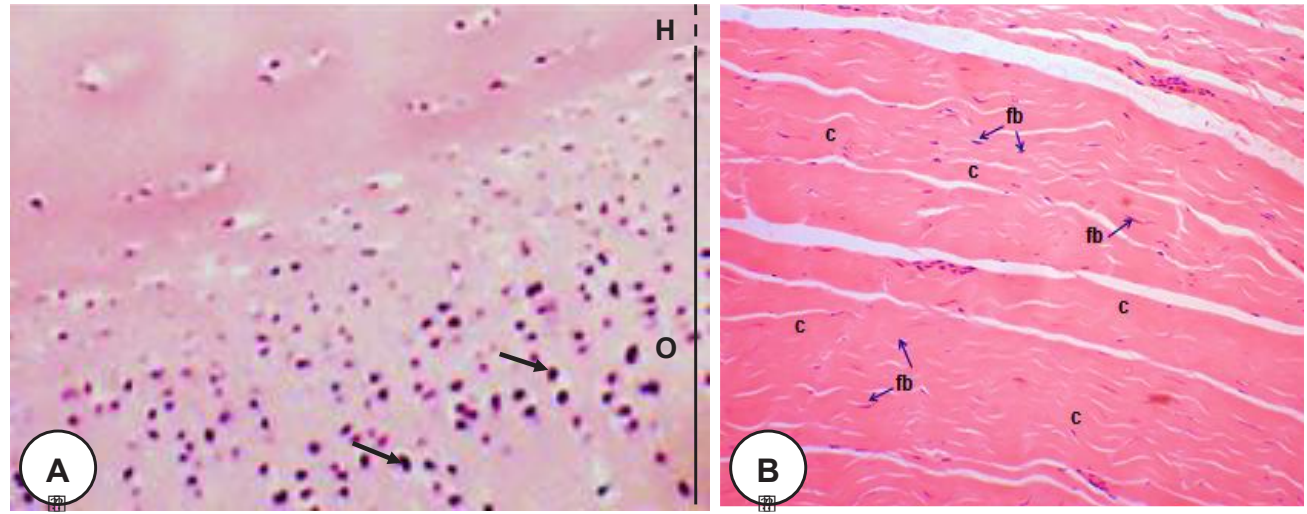

Fig (5): Light micrograph of the crocodile quadrate-articular joint, A. higher magnification of (Fig. 4/A) showing the transitional layer $(\mathrm{H})$ and the radial zone $(\mathrm{O})$ between the cartilage and bone of the mandible, (arrows) indicate beginning of the process of ossification of the chondrocytes. B. lateral collateral ligament showing fibrocytes (fb, arrows) interspersed between the layers of the extracellular collagen fibers (c) (H\&E stain; x40)

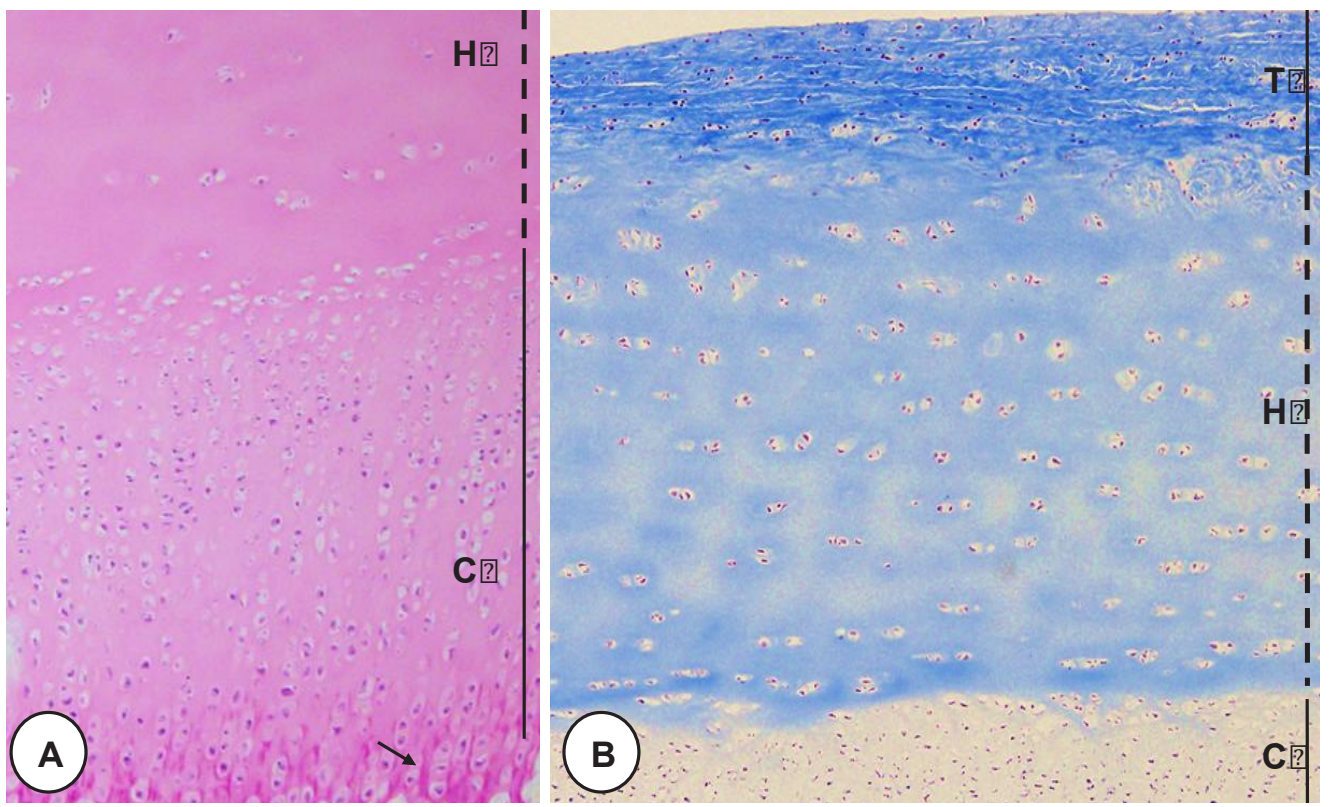

Fig (6): Light micrograph of the articular surface of the crocodile quadrate/articular joint showing $\mathbf{A}$. intensive PAS reaction at the end of the calcified cartilage layer denotes the bone (arrow) (PAS reaction; X40). B. showing the three distinctive layers; (T) tangential layer, $\mathbf{( H )}$ hyaline cartilage layer and $(\mathbf{C})$ calcified layer (Masson's trichrome stain; X20) 


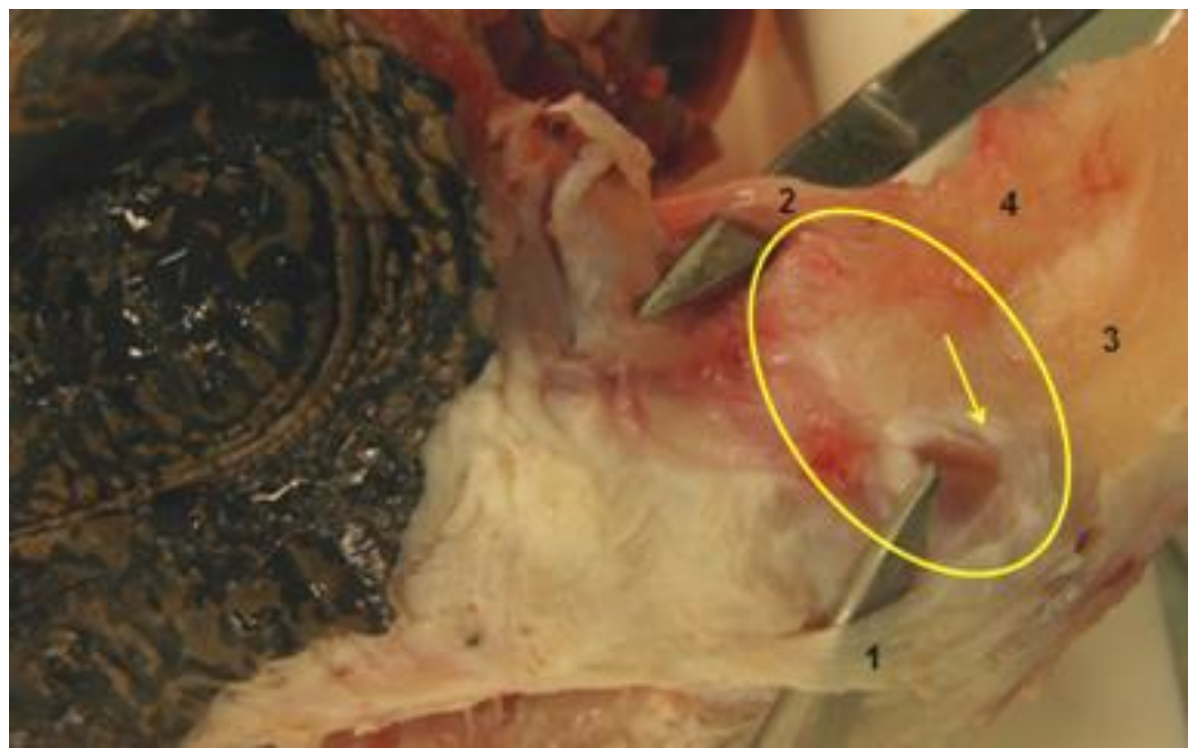

Fig (7): Fresh dissected head of the $\boldsymbol{C}$. porosus showing: lateral (1) and medial (2) collateral ligaments of the left quadrate/articular joint (3) retro-articular process, (4) remnants of the M. depressor mandibulae. The oval circle indicates the joint area; the yellow arrow indicates the opened joint capsule and part of the articular surface covered by the articular cartilage.

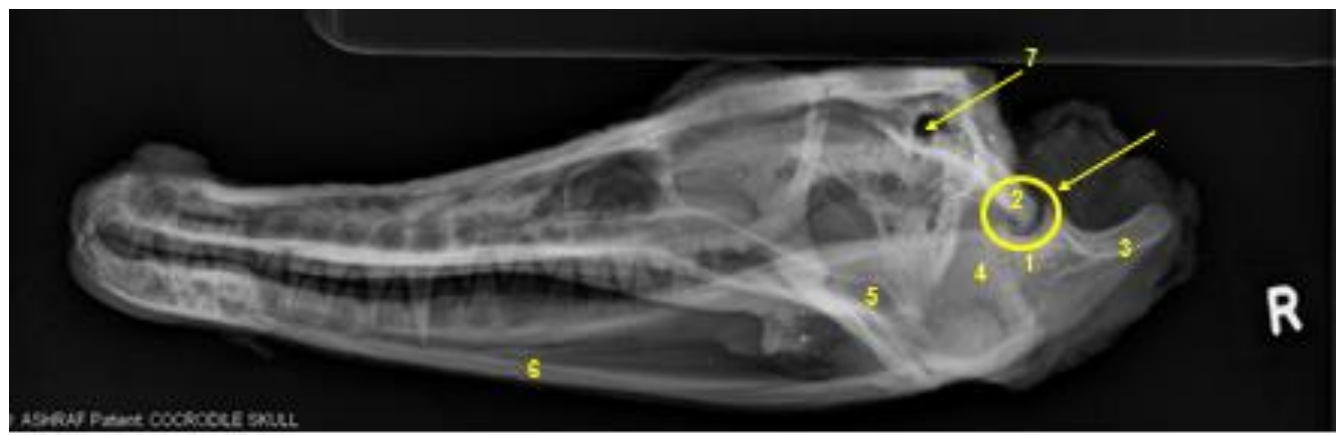

Fig (8): Latero/medial radiograph of the saltwater crocodile (Crocodylus porosus) showing:

1 articular bone, 2 quadrate bone, 3 retro-articular process 4 angular bone, 5 external mandibular fenestra, 6 dentary, 7 cranio-quadrate passage. Arrow indicates the quadrate/articular joint,.

\section{Correspondence address:}

Prof. Dr. A. S. Saber

Email: saberashraf_2@yahoo.com 


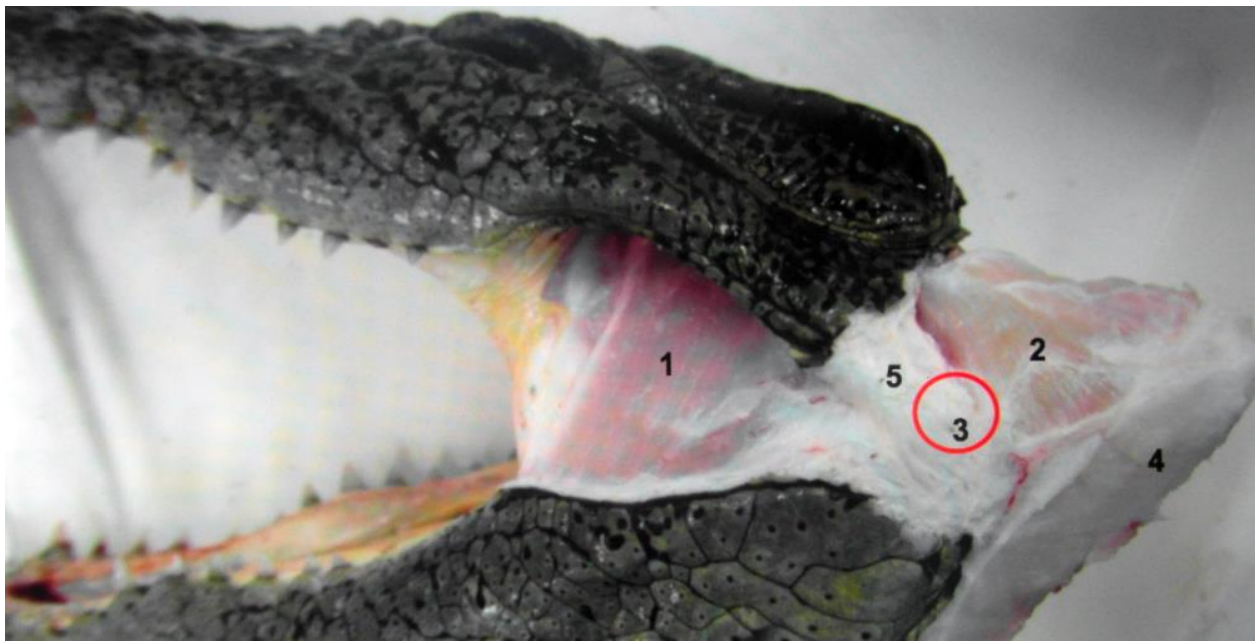

Fig (9): Superficial dissection of the jaw musculature of the $C$. proposes.

$1 \mathrm{M}$. adductor mandibularis externus superficialis, $2 \mathrm{M}$. depressor mandibulae, 3 quadrato/articular joint, 4 retroarticular process, 5 quadrate bone.

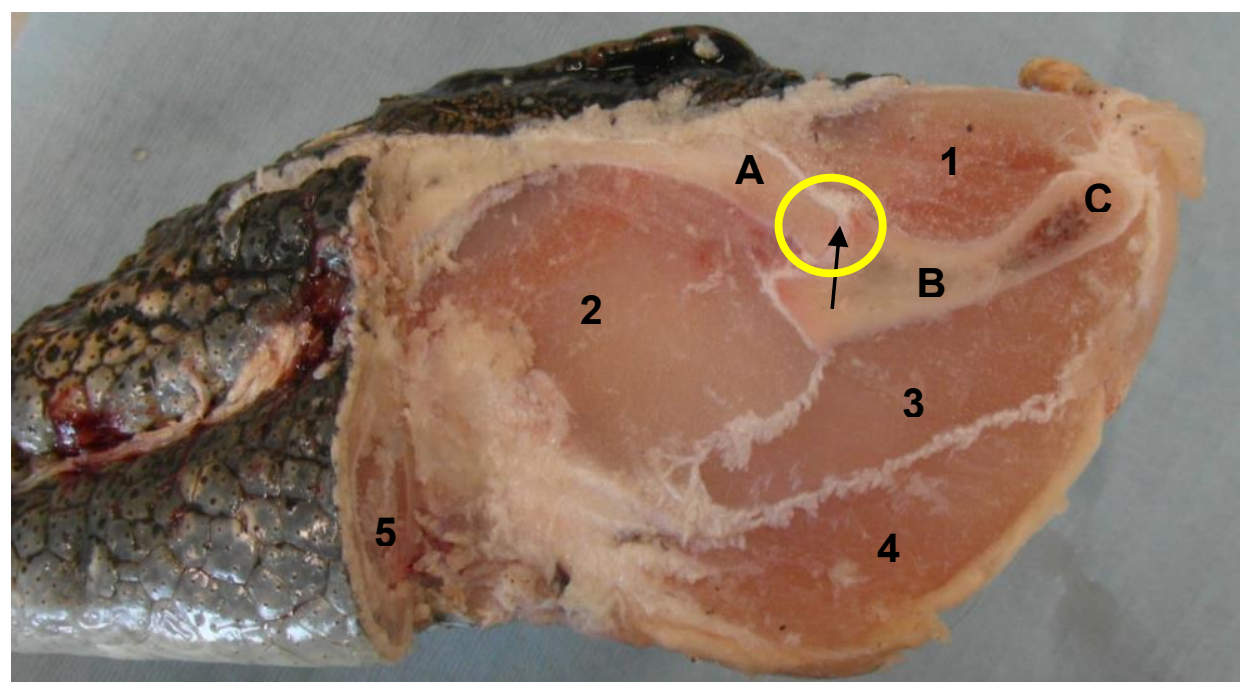

Fig (10): Sagittal section in the caudal part of a frozen head of C. proposes showing the voluminous complex muscles surrounding the quadrate/articular joint.

$1 \mathrm{M}$. depressor mandibulae, $2 \mathrm{M}$. adductor mandibularis (externus superficialis, media, profundus), $3 \mathrm{M}$. adductor mandibularis caudalis \& $4 \mathrm{M}$. pterygoideus ventralis, $5 \mathrm{M}$. intramandibularis,

A quadrate bone, B articular bone. $\mathrm{C}$ retro-articular process. The arrow indicates the joint position. 